\title{
Teaching Point Analysis on Advertisement Design of Shopping Mall
}

\author{
Kai Wei \\ Eastern International Art College \\ Zhengzhou University of Light Industry \\ Zhengzhou, China
}

\begin{abstract}
With the rapid development of commercial advertisement industry, the application of advertisement design is more and more widely, and in course teaching, relative to the advertisement design whose main requirement is posters of print advertisings, the advertisement design of shopping malls undoubtedly involves more faces and more content. According to their personal profession characteristics, and in combination with many aspects such as the design point, elements and handpainted font of shopping mall advertisement, simply analyzes the advertisement design of shopping malls.
\end{abstract}

Keywords-advertisement design of shopping mall; design features of shopping mall; components of advertisement of shopping mall

\section{INTRODUCTION}

Advertisement of Shopping Mall generally can be included as two kinds of generalization and narrowed meanings, and the shopping mall advertisement from broad sense refers to advertisement materials set around and inside the sales sites and in places where commodities display such as the plaque in shops, and the shop windows and decoration, and inflatable advertisement and scrolls hanging outside the storefront, and the decoration, display, poster advertising, service indication, advertisement periodicals issued by stores, advertising performance and broadcast, videos and electric advertisement of advertising board. The advertisement of shopping mall from the broad sense just refers to the sales counters set in purchasing place and retail shop and the advertisement media hanged, put and displayed around commodities which can promote the sale of commodities.

To put it simply, at large advertisement design of generalized shopping place covers all minor details publicized by products in daily life, including some exhibition and display. Generally speaking, the advertisement of shopping mall, in a narrow sense, refers to print advertisement about computers and freehand sketching. At present the courses in the market can be divided into two types, and the first kind is the content is relatively many and diverse, from theory teaching to the manufacture of poster to the operational process of computers, which is partial to the teaching material of design course of advertisement design, The another kind lays particular emphasis on hand-painted posters, from hand-painted poster font to analyze, explain the writing method of hand-painted posters font and the production process of posters. Normally, the former is relatively suitable for teaching subject of arts, and the latter lays particular emphasis on some higher vocational colleges, but with the subdivision of arts discipline, different universities and colleges have different teaching aims, and what problems can be settled for advertisement design course, and each university and college certainly have their own teaching arrangement, which is let students know about the process of origin and development, and at last freehand sketching make a printing plane advertisement which is relatively similar to course assignment of advertisement design, or highlight the hand-painted features of hand-printed font in advertisement design of shopping mall which focuses on the explanation and study of technique, and the operation demand considers hand-painted posters as training requirements? At present computers have gained ground in each corner of our life, and there are huge changes happening in design profession, and the thought of designers and audiences become more and more wider, and the traditional "freehand sketching" has aroused a great challenge of facilitation-manufacture of computers but business freehand sketching is the basic skill that design students need, and provides a more solid basis for design. How to coordinate the proportion and relationship in project curriculum of advertisement of shopping mall in computer manufacture and freehand sketching, and what problems can be settled for project curriculum of shopping advertisement and draw back the differentiation of similar courses from advertisement design, which is a matter that is worthy of being considerable.

\section{Teaching Points Of Advertisement Design OF SHOPPING PLACE}

The types included in shopping advertisement design are many such as plane, suspension and DM, and on campus practicing plane selling advertisement, and there are two ways of late-stage printing and hand-painted drawing of computer production. Now most universities and colleges' selling agency advertisement design courses will take computer production as the principal thing, firstly, computer production is the tendency, and the current designs are all without computers, secondly, the number of materials of design resource is more and more, and every kind of font object library is born at the right moment and can reach the effect of some hand-drawn types, which results in students just focus on the exposition of some theories, the selection of computer corpus, and as the bright spot of advertising design of shopping 
place, but the creativity and expression of hand-drawn type are ignored.

For the design of advertisement of shopping place, we should treat them with a development sight. First, traditional shopping mall advertisement design has a complete theoretical basis such as paying attention to the preliminary planning, copywriter plans, and page layout of shopping mall advertisement, cultivate students' skill and ability of mapmaking quickly and batch quantity, and ask students to have a complete scheme, originality and manufacture, for increasing students' cognition of shopping mall advertisement and understanding of types, there have some reasonable scientific nature, which is teaching advantages that need to be retained and also very useful to hand-painted font and needs to be inherited and developed, but the design of freehand sketching more focuses on cognition and command of writing of characteristics, writing structure, and character strokes, which is similar to font design, but not the same as font design, based on the basis of personal writing habit, and according to the writing method of typefaces such as regular script, movable type, outline letters, and variant fonts, make some font changes, compared with the creativity of font design, hand-painted font more focuses on the humanity of typefaces, and the emotion and comfortableness revealed from each brushstroke are cannot comparable in word stocks whose resources are abundant in computers. With the incessant development of digitized information, today's decoration and diversity of information era flattening are widely used with constantly reduced, compact, and individualized graphic language. The character design itself of hand-painted font is so personalized and accommodates the need of industry development, and mastering the hand-painted font not only this course can have a good harvest, and a new cognition of color matching, and, at the same time, actively master some font design method with more expressive force and individuation for words, which are one of basic three elements of graphic design.

\section{THE MATERIAL PREPARATION OF ADVERTISEMENT DESIGN Of SHOPPING PlACE}

The design of advertisement of plane stores, no matter the manufacture and output of computers or adopting mark pen hand drawing will consider two-dimensional flat paper media as main carrying object, while the range of three-dimensional shopping place advertisement is more broader, and each kind of display advertisement of goods shelves, the counter of advertising, model advertising, outside merchandising location such as advertising board, indicator, hanging of window display, light box, and neon light all can be called as advertising design of three-dimensional shopping place. The material range of manufacturing three-dimensional store advertising are very wide, roughly including materials such as paper characteristics, weights of cloth, wood, plastics, metal and sound \& light and electricity multimedia display.

Combining the teaching reality, and considering the manufacture technology and cost, students' manufacture, and paper quality, weight of cloth, and plastics, especially the weight of cloth and plastics, not only the color of weaving is abundant and bright-colored, but also the made things are lovely and lifelike, which can be used repeatedly, can be used, and the period of use is long and suitable for any companies and any industries as advertising campaign and donation. According to the requirement of publicity, KT foam board can be made into different shapes, because its light-quality and lively exhibition effect and the characteristic of easy-to-buy, which receives the love of classmates, and at the same time, suitable for the popularity of fast moving consumer goods, interpreting perfect details, and after later-stage membrane, the frame has common waterproof function and can lengthen the image life. For PVC plate, in addition to having all advantages of KT plate, the weight is increase which is not easily blown down by wind and the strength also increases drastically, which are not easy to be deformed and broken off.

During the manufacture process of conducting stereoscopic shopping place advertisement by students, in addition to considering the need of materials by theme itself and the controllability of materials through manufacture by him/her. The most importance is that how to grasp the high unity of colors, typefaces and visual effects in print aids and stereo display and how to combine the creativity of plans and stereoscopic formal perfectness.

At present in markets, relevant books of shopping mall advertisement design generally can be included three types, the first type of content is relatively abundant from the summary, scheme, visual theory, design principle, color application to advertising production of hand-painted stores, advertising production of three-dimensional stores, design basis of advertising and computers of shopping places, the excellent and complete advertisement and case appreciation and the information is very complete. The second type mainly focuses on the display of freehand sketching typeface and techniques, and these kinds of books give priority to hand-drawn type techniques, including frequently-used upright letters, living words, software words, light face, and other creative typefaces created by excellent designers, which takes handwriting and graphs as the principal thing. The third type is albums of painting and dictionaries, including abundant advertisement design examples of festival stores, generally through several aspects such as typeface, head-letter combination, and poster, which will provide reference and help for the work and study of designers of shopping mall advertisement and vast art lovers.

Generally speaking, as a teaching material, the first kind of books are more chosen as teaching materials, but the content of books are detailed and complicated, containing the course information such as too many color composition, plate design, advertisement design, computer aided design, but the expertise is relatively week. Combining the current situation of professional development, by and large before courses, students all contact these pre-posed relevant subjects, and the course repetition of the second kind of books which focus on freehand sketching, and speaking from the professionalism and practicability, for my part, the latter is superior to the former, which helps more to this kind of course designed by shopping place advertisement. The third kind belongs to reference books corresponding to people who have certain foundation just for reference and consultation, and these kinds of books are suitable for instruction after class. 


\section{CONCLUSION}

Compared with advertising design course whose main work requirement is posters of print advertisement, the project curriculum of advertising of shopping place undoubtedly involves more faces and content consequently different universities and colleges have their own different emphases, because at present relevant professional supporting facilities of most universities and colleges are not thorough, students cannot realize the manufacture of some three-dimensional advertisement, display rack advertisement, and hang advertising, no matter in technology and in material they still stay at the stage of creative drafts, in a sense, they can put the advertisement in shopping places at a slightly embarrassing circumstance, and reviewing current market demand, an art designer needed by the general market store shall give priority to exhibition and arrangement, and the skilled talents are needed with a very strong comprehensive practice ability. Pay attention to the link of the front and back chain before the oncampus, and deal with problems that shall be settled by each course, and in teaching course of computers, solve the basic operation command of design software, and in graphically creative courses grasp the method of brainstorming, and in advertising design courses, through applying the processing work of applying computers to do images well, and in design courses of shopping place advertisement settle hand-drawn type and graphic design, and break monotonous work stock of computer, and in daily life, more observation, more attention, more contact and more accumulation are needed to slowly and gradually enhance the design capabilities.

\section{REFERENCES}

[1] Wang Jing, POP Advertisement in Shopping Place, Youth Literator 2013-08

[2] Lan Bowan, The Future of Advertisement of Shopping Place: Frequency Focus, Observation of Advertising Market 2008-09

[3] Sun Guang, The Design and Marketing of Commercial Store, Market Modernization 2012-03 